University of Rhode Island

DigitalCommons@URI

Mechanical, Industrial \& Systems Engineering

Faculty Publications

2021

\title{
Effects of Water Saturation and Low Temperature Coupling on the Mechanical Behavior of Carbon and E-Glass Epoxy Laminates
}

James LeBlanc

Paul Cavallaro

Jahn Torres

David Ponte

Eric Warner

See next page for additional authors

Follow this and additional works at: https://digitalcommons.uri.edu/mcise_facpubs

Creative Commons License

c) (i) $९($

This work is licensed under a Creative Commons Attribution-Noncommercial-No Derivative Works 4.0 License.

\section{Citation/Publisher Attribution}

J. LeBlanc, P. Cavallaro, J. Torres, D. Ponte, E. Warner, I. Chenwi, A. Shukla,Effects of Water Saturation and Low Temperature Coupling on the Mechanical Behavior of Carbonand E-Glass Epoxy Laminates, International Journal of Lightweight Materials and Manufacture, https://doi.org/10.1016/ j.ijlmm.2021.05.001

Available at: https://doi.org/10.1016/j.ijlmm.2021.05.001

This Article is brought to you for free and open access by the Mechanical, Industrial \& Systems Engineering at DigitalCommons@URI. It has been accepted for inclusion in Mechanical, Industrial \& Systems Engineering Faculty Publications by an authorized administrator of DigitalCommons@URI. For more information, please contact digitalcommons@etal.uri.edu. 


\section{Authors}

James LeBlanc, Paul Cavallaro, Jahn Torres, David Ponte, Eric Warner, Irine Chenwi, and Aun Shukla

This article is available at DigitalCommons@URI: https://digitalcommons.uri.edu/mcise_facpubs/50 


\section{Journal Pre-proof}

Effects of Water Saturation and Low Temperature Coupling on the Mechanical Behavior of Carbon and E-Glass Epoxy Laminates

James LeBlanc, Paul Cavallaro, Jahn Torres, David Ponte, Eric Warner, Irine Chenwi, Arun Shukla

PII:

$$
\text { S2588-8404(21)00018-4 }
$$

DOI: https://doi.org/10.1016/j.ijlmm.2021.05.001

Reference: IJLMM 157

To appear in: International Journal of Lightweight Materials and Manufacture

Received Date: 19 December 2020

Revised Date: 26 April 2021

Accepted Date: 4 May 2021

Please cite this article as: J. LeBlanc, P. Cavallaro, J. Torres, D. Ponte, E. Warner, I. Chenwi, A. Shukla, Effects of Water Saturation and Low Temperature Coupling on the Mechanical Behavior of Carbon and E-Glass Epoxy Laminates, International Journal of Lightweight Materials and Manufacture, https:// doi.org/10.1016/j.jilmm.2021.05.001.

This is a PDF file of an article that has undergone enhancements after acceptance, such as the addition of a cover page and metadata, and formatting for readability, but it is not yet the definitive version of record. This version will undergo additional copyediting, typesetting and review before it is published in its final form, but we are providing this version to give early visibility of the article. Please note that, during the production process, errors may be discovered which could affect the content, and all legal disclaimers that apply to the journal pertain.

(C) 2021 The Authors. Publishing services by Elsevier B.V. on behalf of KeAi Communications Co. Ltd. 

of Carbon and E-Glass Epoxy Laminates

4 James LeBlanc ${ }^{\text {a }}$, Paul Cavallaro ${ }^{\mathrm{a}}$, Jahn Torres ${ }^{\mathrm{a}}$, David Ponte ${ }^{\mathrm{a}}$, Eric Warner ${ }^{\mathrm{a}}$, Irine Chenwi , and Arun Shukla ${ }^{\mathrm{b}}$

${ }^{a}$ Naval Undersea Warfare Center (Division Newport), 1176 Howell St, Newport RI, 02841

${ }^{b}$ Dynamic Photo Mechanics Laboratory, Department of Mechanical, Industrial and Systems 


\section{Effects of Water Saturation and Low Temperature Coupling on the Mechanical Behavior of Carbon and E-Glass Epoxy Laminates}

ABSTRACT

6 An experimentally based study has been conducted to quantify the effects of coupled water

7 saturation and low temperatures on the quasi-static and dynamic mechanical behavior of E-Glass

8 and Carbon Epoxy laminates. The relative performance of the materials as a function of water

9 saturation and decreasing temperature was characterized through detailed experiments,

10 specifically in-plane (tensile / compressive) and shear material properties, static and dynamic

11 Mode-I fracture, and impact / flexure after impact strength. In the investigation temperatures

12 from Room Temperature $\left(20^{\circ} \mathrm{C}\right)$ down to arctic seawater and extreme ocean depth conditions (-

$132{ }^{\circ} \mathrm{C}$ ) were evaluated. The materials utilized in the study, Carbon/Epoxy and E-glass/Epoxy, are

14 chosen due to their primary interest to the underwater vehicle and marine industry communities.

15 The results of the quasi-static and dynamic material experiments show that all properties are

16 affected by both water saturation and decreasing temperature, although the trends are specific to

17 the property under consideration.

\section{INTRODUCTION}

22 Advanced composite materials exhibit desirable characteristics which make them viable

23 candidates for utilization in harsh marine environments. These materials produce components

24 that have high strength to weight ratios, lighter overall weight, superior resistance to corrosion,

25 and overall reductions in required maintenance. However, there are also unique considerations 
26 that must be taken when using these materials in the design of a structure. These include reduced

27 resistance to impact damage and cyclic loading conditions, post damage residual strengths,

28 complex failure and damage mechanisms, repair difficulty, and stringent certification processes.

29 The understanding of the performance of these materials when operating in extreme marine

30 environments is key in ensuring a structurally adequate design that will retain robustness

31 throughout the intended life cycle. The focus of this paper is on the conditions found in arctic

32 environments, deep ocean depths, and applications with long seawater exposure times such as

33 drilling operations. The conditions associated with these environments include near freezing

34 seawater temperatures and water ingression into the structural laminates. The objective of the

35 research is to quantify the mechanical and damage behavior changes of these advanced material

36 systems due to water ingression, and decreasing temperature down to the lowest expected water

37 temperatures of the arctic / deep ocean environments. The specific quantities of interest

38 presented in the study consist of those that potentially affect operating capabilities of submerged

39 components/structures arising from low temperature/water ingression exposures, namely

40 material strength (tensile, shear, compression), damage resistance (fracture toughness, crack

41 propagation/stability), and impact loading resistance.

44 The understanding of the complex mechanical and fracture characteristics of advanced 45 composite materials is generally much more limited than the knowledge associated with 46 historical metallic materials. This limited understanding can be compounded by the introduction

47 of use in long term submergence and low temperature conditions. The use of polymer based 48 materials in cold and arctic temperature environments results in higher stiffnesses but oftentimes 
49 lower toughness properties which may lead to the onset of unique failure mechanisms. When

50 considering the design of structures and vehicles comprised of composite materials to be

51 operated in a cold water environment there is a certain need to understand the unique relations

52 ships between lamina stresses and distributions, the mechanics of the interlaminar ply interfaces,

53 water absorption behavior, and fracture properties. In low temperature cases where impact type

54 loading, such as wave slap or collisions, is a concern there is a greater desire to improve the

55 fracture toughness of the materials and associated laminates. These material choices and

56 characterizations are typically made and driven by the results of detailed laboratory testing in a

57 controlled environment. Future advancements in the knowledgebase of the effects of arctic

58 ocean type temperatures and long term water saturation on the failure characteristics of advanced

59 composite materials will further the expanded use of these material in marine applications.

60 Prior investigations of arctic environment temperatures on composite materials have primarily

61 been conducted on dry laminates at temperatures down to the cryogenic regime. Walsh et al. [1]

62 evaluated the effects of temperatures down to $4 \mathrm{~K}$ on the tensile, compression, and shear

63 characteristics of an E-Glass/Epoxy laminate and reported increasing strength and stiffness with

64 decreasing temperatures. Kim et al. [2] evaluated the cryogenic temperature effects on a T700

65 Carbon/Epoxy laminate, including thermo-mechanical cycling, and found slight increases in

66 material stiffness with corresponding decreases in material strength with decreasing temperatures

67 down to $-150^{\circ} \mathrm{C}$. The influence of low temperatures on the dynamic behavior of composite

68 materials have been studied by several researchers. Sanchez-Saez et al. [3] investigated the

69 effects of temperatures down to $-150^{\circ} \mathrm{C}$ on the static and dynamic flexural behavior with a three-

70 point bend configuration. Consistent with prior studies, the strength and energy capacity

71 decreased with decreased temperature with the flexural modulus being relatively unaffected. 
72 Ricciardi et al. [4] considered the effects of temperatures down to $-50^{\circ} \mathrm{C}$ on the interlaminar

73 shear strength and the flexure under impact performance of a woven basalt fiber based laminate.

74 The study showed increased stiffness of the laminates but also a corresponding increase in

75 delamination damage with decreasing temperature. Garcia-Gonzalez et al. [5] performed low

76 velocity impact experiments on short carbon fiber reinforced PEEK laminates at temperatures

77 ranging from $25^{\circ} \mathrm{C}$ to $-75^{\circ} \mathrm{C}$. The study identified a ductile-to-brittle transition in the material

78 damage and a quantifiable decrease in energy absorption at the lower temperatures.

79 An investigation conducted by Kichhannagari [6] highlighted that at low temperatures there is a

80 larger level of material micro-cracking for specimens subjected to both uniaxial and biaxial

81 loading conditions as compared to ambient temperature conditions. This was determined to

82 result from matric shrinkage and resulting residual laminar shear stresses due to thermal

83 contraction. The presence of these interlaminar microcracks was found by several researchers

$84[7,8,9]$ to increase material permeability which results in path initiation for absorption of

85 moisture and water with associated material swelling. When subjected to multiple cycles of

86 freezing and thawing in a saturated condition, this swelling effect can serve as the source of

87 stresses that are environmentally induced. Coalescence of these microcracks into meso- and

88 macroscale groupings has the pronounced effect of reducing the materials fracture toughness and

89 associated damage performance. A full working knowledge of the freeze and thaw cycle effect

90 is required to support the design and construction of composite structures in low temperature

91 environments. The consideration of fracture toughness performance is of greater concern when

92 impact type loading is expected to be imparted to a composite structure, particularly in low

93 temperature ocean environments. These types of loading events are well suited for evaluation in

94 a controlled laboratory environment through drop tower impact experiments. Results of these 
95 tests may be further utilized for material selection optimization by the understanding of the rate

96 dependent fracture toughness characteristics.

\section{2. MATERIALS}

99 The materials utilized in the current study are consistent with those evaluated in [10] to allow for for meaningfu

100 The fabrics are balanced in the warp and weft directions and are of a greige (untreated)

101 condition. The E-Glass and Carbon fabrics have respective areal weights of $190 \mathrm{~g} / \mathrm{m}^{2}(5.61$

$\left.102 \mathrm{oz} / \mathrm{yd}^{2}\right)$ and $199 \mathrm{~g} / \mathrm{m}^{2}\left(5.88 \mathrm{oz} / \mathrm{yd}^{2}\right)$. All laminated panels utilized ProSet 125/226 laminating

103 epoxy and were manufactured in a press with curing conducted at $82^{\circ} \mathrm{C}\left(180^{\circ} \mathrm{F}\right)$ under $140 \mathrm{kN}$

104 (14 tons) of load. Panels were manufactured in plate thicknesses of 2.54 and $5.08 \mathrm{~mm}(0.1$ and 1050.2 in.) to support the specifications of the pertinent test standards.

106

107

108

109

110

111

112

113 The investigation into the effects of water ingression on the mechanical behaviors of FRP

114 composites required that the test specimens were immersed in a water bath until fully saturated.

115 This water-saturated condition mimics the effects of long-term water submersion for a period of 116 months. The specimens were placed in a bath of distilled water over a period of 4 to 6 months

\section{Figure 1 - Plain Weave Fabric Architecture (Courtesy of JPS Composites Technical Reference Handbook [11])}

\section{WATER SATURATION METHODOLOGY}

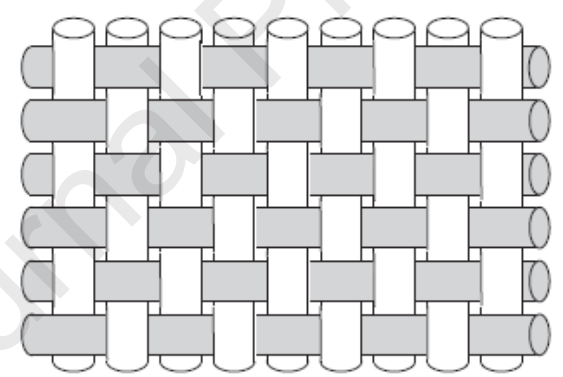


117 until they reached saturation. All specimen surfaces were in contact with water during

118 submersion in the water bath. To accelerate the soaking time, the water baths were placed into

119 ovens at $45^{\circ} \mathrm{C}$. The temperature of $45^{\circ} \mathrm{C}$ was chosen since it is below the FRP composite's epoxy

120 glass transition temperature of $80^{\circ} \mathrm{C}$ previously determined experimentally in [10]. This lower

121 temperature will ensure that the epoxy does not experience physical changes during soaking. To

122 determine when the specimens became saturated, the mass of representative samples from each

123 specimen type was monitored throughout the soak until the change in mass approached a plateau

124 dictated by Fickian diffusion analytical modeling. The samples were held in the water baths until

125 each mechanical test was performed.

126

127

128 The experimental methods utilized in the current study to evaluate the effects of water saturation

129 and low temperatures on the Carbon and E-Glass laminates are consistent with those previously

130 utilized by the authors in [10]. The full details of the mechanical characterization test methods

131 are contained in the previous publication and are summarized in the following section for

132 brevity.

133 4.1 Tension / Compression / Short Beam Shear

134 The effect of coupled water saturation and low temperatures on the stiffness and strength

135 properties of the respective laminates was characterized through controlled laboratory testing

136 consisting of tension, compression, and short beam shear. These material tests were performed

137 in accordance with ASTM D638 (Tension) [12], ASTM D3410 (Compression) [13], and ASTM

138 D2344 (Short Beam) [14]. Each respective material characterization test (stiffness and strength)

139 was performed at temperatures of $20^{\circ} \mathrm{C}, 5^{\circ} \mathrm{C}$, and $-2^{\circ} \mathrm{C}$. An Instron ${ }^{\circledR}$ machine operated in 
140 displacement-controlled loading was used in each of the test series and for the cases on low

141 temperatures, an environmental chamber utilizing liquid nitrogen as the cooling source was

142 employed. Prior to the respective mechanical testing all specimens were "Thermally Soaked" for

143 a minimum of one hour in the cooling chamber to bring the specimens to the desired

144 temperature. The details of individual test configurations is shown in Figure 2.

154 insert positioned at the mid-plane of the laminate. The real time crack length and crack growth

155 stability were measured through the use of fracture gages (Vishay TK-09-CPC03-003/DP) 
156 bonded to the specimen edges ahead of the crack front. The crack gages consist of 20 individual

157 strands with a spacing of $2 \mathrm{~mm}$ perpendicular to the crack propagation direction and facilitate the

158 calculation of $G_{I C}$. The strands in the gage are ruptured as the crack tip passes through the strand

159 during propagation and the corresponding change in voltage is recorded by the acquisition

160 system. The corresponding load and deflection histories are also recorded by the data system

161 connected to the test machine. The combined data set consisting of force, displacement, and

162 crack length are utilized to characterize the $G_{I C}$ values through the use of the Modified Beam

163 Theory (MBT) formulation provided in [16]. The governing MBT equation is given as:

$164 G_{I C}=\frac{3 P \delta}{2 w a}$

165 where $P$ is the load, $\delta$ is the extension, $w$ is the specimen width, and $a$ is the crack length.
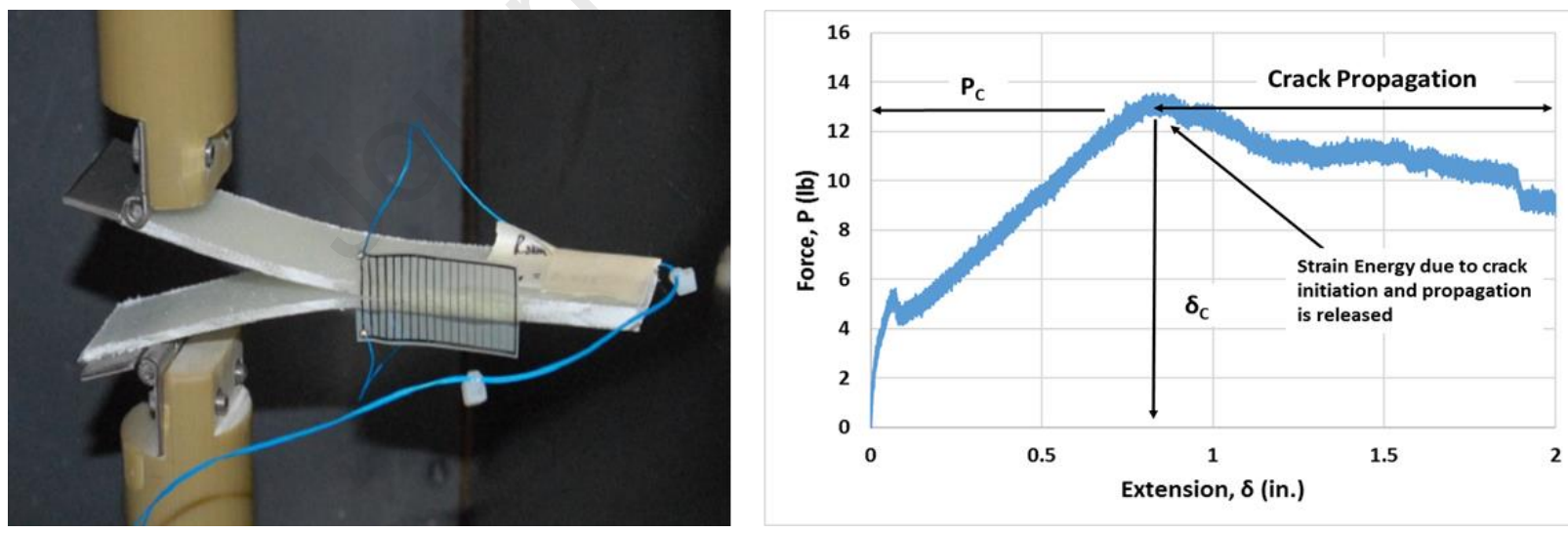

169 Figure 3 - Mode-I Fracture Test Configuration and Typical Load vs. Extension Behavior

$171 \quad 4.3$ Dynamic Mode-I Fracture

172 The dynamic fracture characteristics of the Carbon and E-Glass laminates were obtained

173 using an advanced experimental approach. Dynamic fracture toughness was determined 

using the wedge-insert-fracture (WIF) method [17], which utilized a double cantilever beam 175 specimen geometry combined with a unique Split Hopkinson Pressure Bar (SHPB) setup 176 shown in Figure 4. The specimen had a width of $12.70 \mathrm{~mm}(0.5 \mathrm{in}$.$) and a thickness of 5.08$ $177 \mathrm{~mm}(0.2$ in.) with a Teflon film insert used to create a precrack at the mid plane of the panel. 178 The incident bar was $9.5 \mathrm{~mm}$ (0.375 in.) in diameter, $162 \mathrm{~cm}$ (64 in.) in length and was made 179 of brass. The portion of the wedge insert in contact with the incident bar had a $12.7 \mathrm{~mm}(0.5$ 180 in.) outer diameter and the flat end in contact with the specimens was semi-cylindrical with a 181 diameter of $3 \mathrm{~mm}$ (0.118 in.). The initial crack length (distance from the center of the semi182 cylindrical tip of the inserted wedge to the crack tip), was $4.7 \mathrm{~cm}(1.85 \mathrm{in}$.$) and 4.2 \mathrm{~cm}(1.65$ 183 in.) for the Carbon/Epoxy composite and E-Glass/Epoxy composite, respectively. The full 184 theoretical derivation of this approach is provided in [10]

185 The experiments conducted at $5^{\circ} \mathrm{C}$ and $-2^{\circ} \mathrm{C}$ utilized a wooden cooling box with glass fiber 186 insulation as shown in Figure 5. Compressed air circulated in a copper tube, immersed in dry 187 ice, was used to cool the specimen in the cooling box. The desired specimen temperatures were 188 achieved by controlling the flow rate of the compressed air with real-time measurements of 189 the temperature in the box recorded using an OMEGA K-type thermocouple. Upon the 190 specimen reaching thermal equilibrium with the air in the cooling chamber, the striker was 191 released to create the compressive pulse in the incident bar. Clay was used as a pulse shaper 192 on the striker end of the incident bar to eliminate the high frequency components of the 193 compressive pulse, thus effectively suppressing vibrations on the specimens caused by 194 impact loading. 

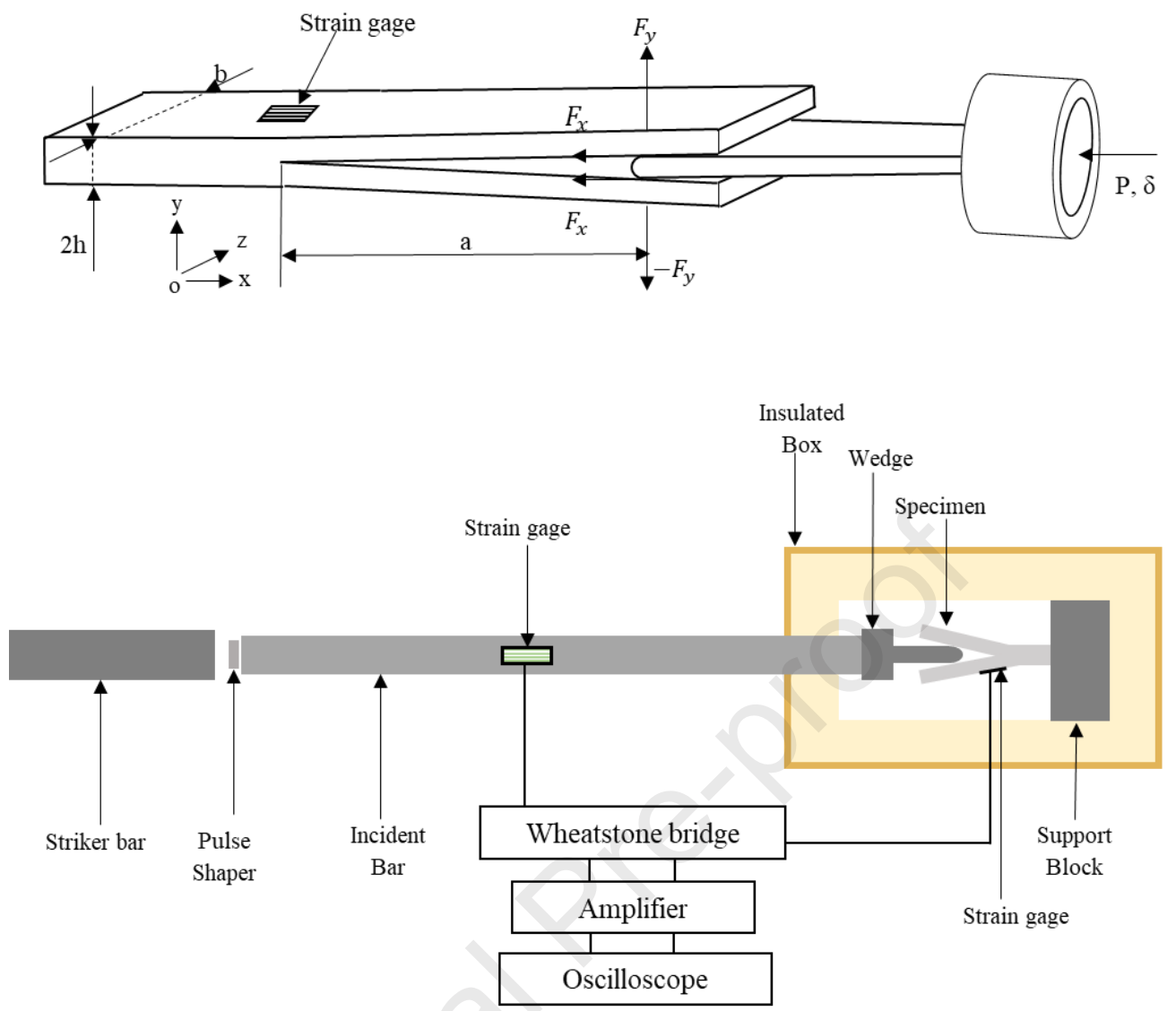


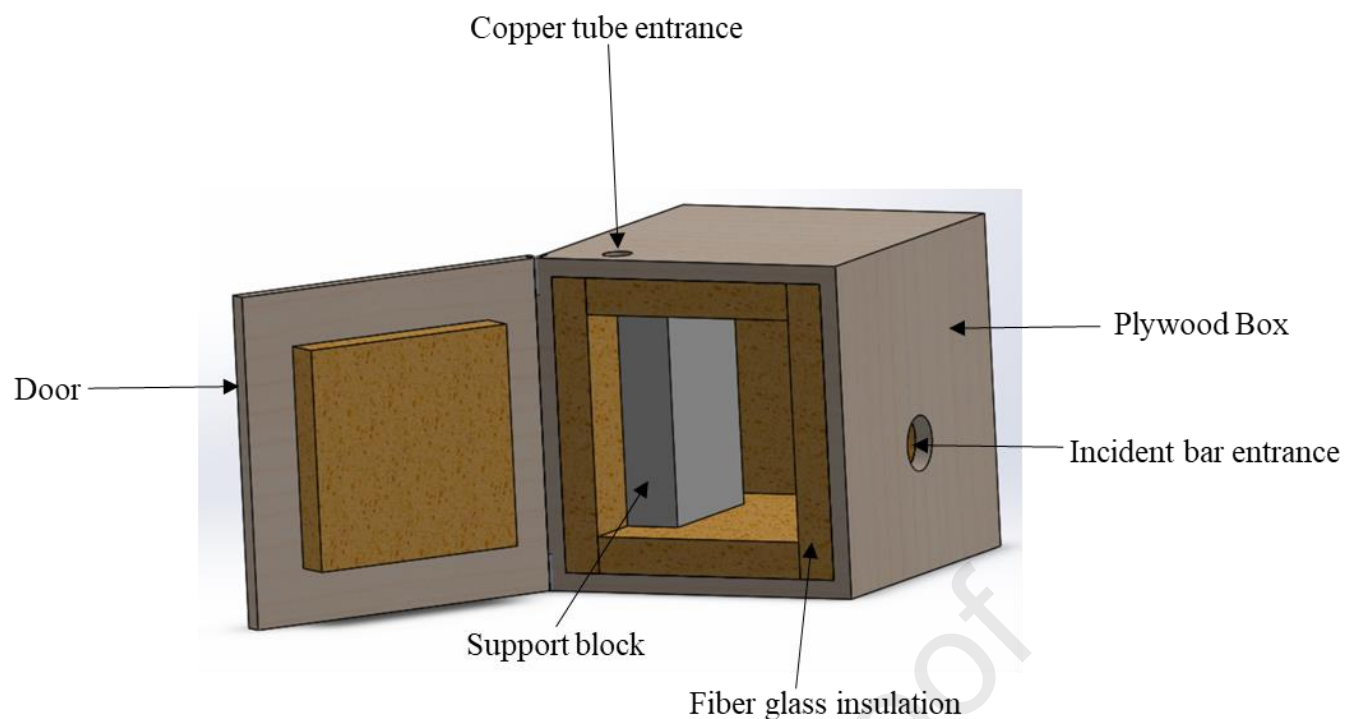

Fiber glass insulation

207 The Mode-I critical strain energy release rate, $G_{I c d}$ for the WIF specimen is calculated from

208 Equation 2, using the maximum value of strains attained. In these experiments and in lieu of 209 using the strain rate, the loading rate was calculated as the time derivative of the energy release 210 rate.

$$
G_{I c d}=\frac{h \varepsilon_{s}^{2} E_{x x}(a+e)^{2}}{3 a^{2}}
$$

212 where $h$ is the plate half thickness, $\varepsilon_{s}$ is the maximum strain from the strain gage, $a$ is the initial

213 crack length, $E_{x x}$ is the Young's modulus in the longitudinal direction, $e$ is a correction factor for

214 local deformation around the crack tip and taken to be $3 \mathrm{~mm}(0.118 \mathrm{in}$.) in these experiments

215 4.4 Impact and Flexure after Impact

216 The effect of water saturation coupled with decreasing temperature on the impact response of the

217 respective composite materials was quantified though a two part test series. The samples were

218 first impacted through the use of a instrumented drop tower to induce damage and was followed

219 by a 4-point flexure test of the damaged samples. This approach is identical to the method 
220 previously utilized in [15] with the primary objective fo the impact tests being to generate barely

221 visible impact damage (BVID) levels in the test specimens. A summary of the procedure is

222 provided as follows.

223 A Instron Dynatup ${ }^{\circledR}$ Model 9210 instrumented drop test machine was used in the conduct of the 224 impact tests. The specimens were of dimensions $139.7 \mathrm{~mm}$ x $12.7 \mathrm{~mm}$ x $0.508 \mathrm{~mm}(5.5 \mathrm{in} . \mathrm{x} 0.5$

225 in. $x 0.2$ in.) and had the material warp direction oriented along the length of the samples. The

226 drop tower impact head was fitted with a $6.35 \mathrm{~mm}(0.25$ in.) radius line-load impactor and an

227 accelerometer recorded the force time history during the impact event. During the impact testing

228 the samples were configured in a three-point flexure arrangement with a span length between

229 supports of $5.08 \mathrm{~cm}(2 \mathrm{in}$.$) as shown in Figure 6. The objective purpose of the drop tower test$

230 was to: (1) record the force-time history of the impact head during contact with the composite

231 specimens and (2) impart an observable level of damage to the specimens for the subsequent

232 four-point flexural after impact testing. All specimens were "Thermally Soaked" for a minimum

233 of one hour in a low temperature chamber to bring the specimens to the desired temperature after

234 which the drop tower test was immediately conducted. The impacted specimens were then

235 returned to the thermal chamber to maintain the temperature prior to the subsequent flexural

236 tests. Preliminary test runs were conducted at room temperature to determine the appropriate

237 levels of impact energy that result in BVID but short of complete failure of the specimens.

238 These trials identified the energy levels to establish an acceptable energy threshold (AET) for

239 producing BVID. The impact energy was determined for the room temperature specimens and

240 used for the low temperature tests. The respective impact energies used in the study were 5.3J

241 for the Carbon laminates and 8.6J for the E-Glass laminates. The post-impact material damage 
242 levels for the drop test conducted at $5^{\circ} \mathrm{C}$ for the Carbon and E-Glass laminates are shown in

\section{$243 \quad$ Figure 7.}

244 Subsequent to the conduct of the impact testing a four-point flexural bending test was conducted

245 on each sample to quantify the coupled water saturation and low temperature effects on the

246 residual flexure strength after impact of the composite materials. The four-point flexure loading

247 was conducted within a thermal chamber connected to the Instron test machine with the flexure

248 test temperature corresponding to the drop tower test. The span length used in the flexure tests

249 was $114.3 \mathrm{~mm}$ and the span between loading supports was $38.1 \mathrm{~mm}$ with the loading fixture 250 shown in Figure 6.
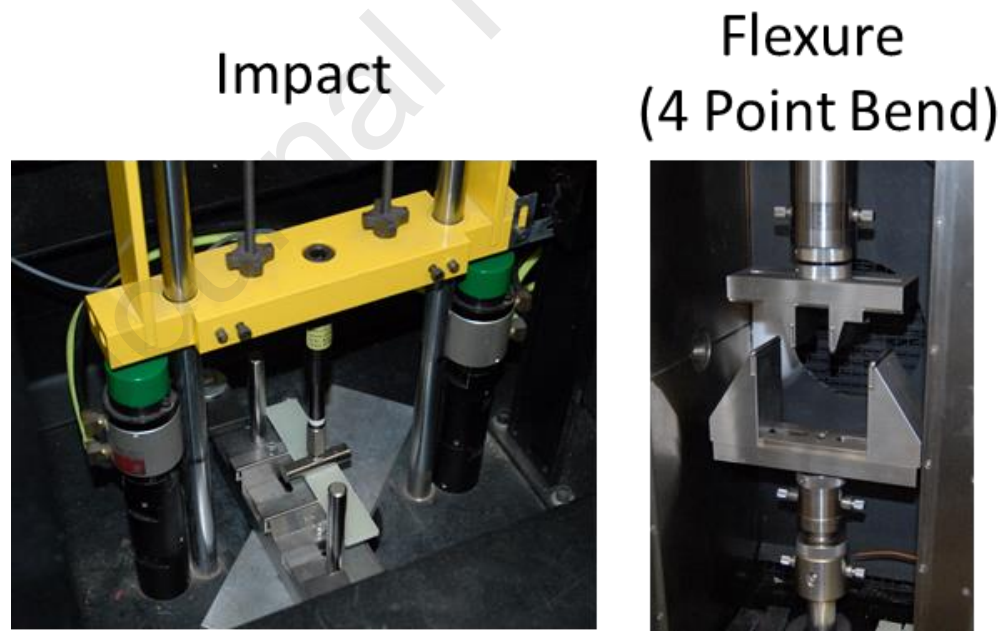


\section{E-Glass}

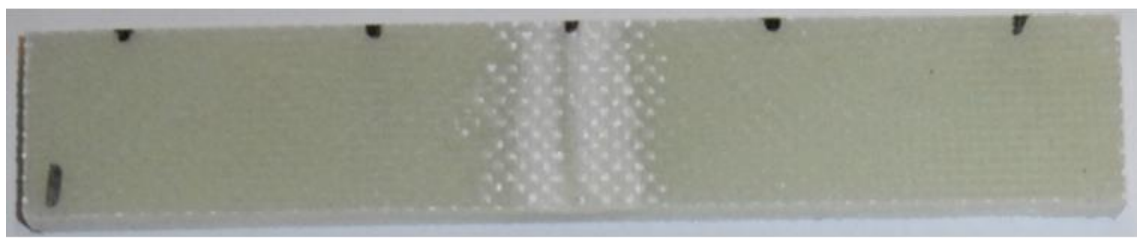

\section{Carbon}

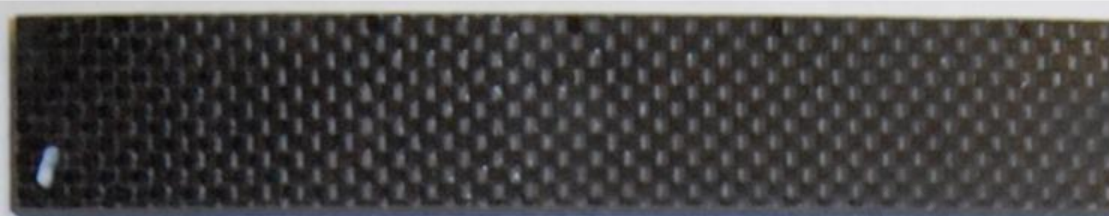

Figure $7-5^{\circ} \mathrm{C}$ Impact Test Damage Levels

\section{EXPERIMENTAL RESULTS}

\subsection{Tensile and Compressive Modulus and Strength}

262 The stress-strain behavior of the saturated and dry Carbon and E-Glass laminates under tension

263 and compression loading are shown in Figure 8 for the tests performed at $5^{\circ} \mathrm{C}$. While the five

264 specimens tested in each condition showed high repeatability, only a single representative

265 specimen is shown for clarity of the respective plots. While specific details of the material

266 performance under each type of loading are discussed in the subsequent section this plot

267 highlights the key differences in relative material behavior. Firstly, Both the Carbon and E-Glass

268 are significantly stiffer in tension than compression, as well as have larger tensile strengths than

269 compression strength. However, It is also noted that the compressive behavior of both materials,

270 while less stiff, exhibits nearly two times the overall toughness than the corresponding tensile

271 behavior. 

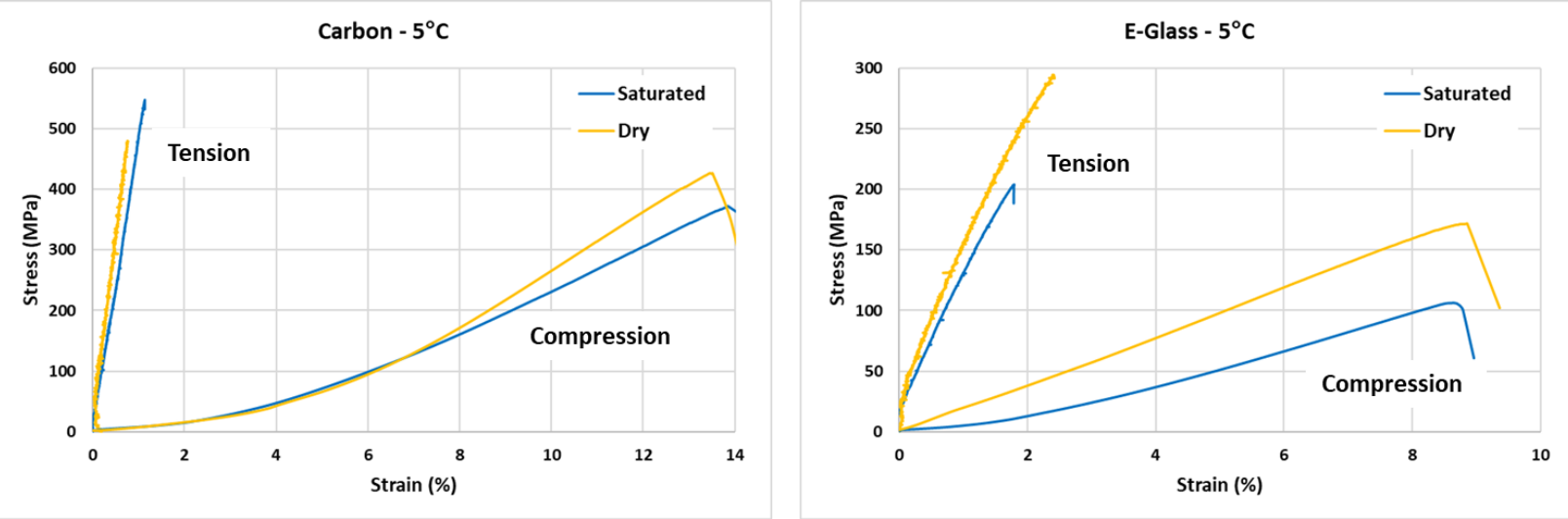

Figure 8 - Tension and Compression Behavior of Carbon and E-Glass Laminates at $5^{\circ} \mathrm{C}$

The influence of low temperature coupled with full water saturation on the tensile modulus and strength of the Carbon and E-Glass laminates are shown in Figure 9. All tensile tests on the saturated laminates were performed at $20^{\circ} \mathrm{C}, 5^{\circ} \mathrm{C}$, and $-2^{\circ} \mathrm{C}$ for consistency with the results presented previously in [10]. In all cases, both dry and fully saturated, the testing exhibited a linear material response up to failure with a brittle and rapid failure exhibited at the point of maximum loading. Consistent trends are evident in material moduli and strength responses over

282 the temperature range considered in the study for the saturated and dry conditions, although the 283 magnitudes are affected by water ingression. The mechanical characterization results highlight 284 that in terms of stiffness performance, the Carbon is on average five times stiffer than the 285 corresponding E-Glass laminate in both dry and saturated states. In terms of strength 286 comparisons, the Carbon is nearly 2 times as strong as the E-Glass in the dry condition and 3 287 times as strong in the saturated condition. The difference in relative ratios in the strength is due 288 to the significant drop in E-Glass strength in the saturated state.

289 The tensile results showed that across the temperature range of consideration, $20^{\circ} \mathrm{C}$ to $-2^{\circ} \mathrm{C}$, the 290 Carbon and E-Glass laminates both exhibit reductions in modulus and strength when saturated 291 with water. Examining the trend in the Carbon results for moduli and strength as a function of 
292 temperature, it is shown that the difference between saturated and dry samples is more 293 pronounced at $-2^{\circ} \mathrm{C}$ than at $20^{\circ} \mathrm{C}$. At $-2^{\circ} \mathrm{C}$ there is a difference of $11.8 \mathrm{GPa}$ in stiffness between

294 the dry and saturated laminates, and a reduction of $70 \mathrm{MPa}$ in strength. Correspondingly, the 295 reduction in stiffness and strength at $20^{\circ} \mathrm{C}$ is $6.9 \mathrm{GPa}$ and $28 \mathrm{MPa}$, respectively. The difference 296 in magnitude changes as a function of both temperature and saturation state indicates a coupling 297 effect as the entrained water expands with decreasing temperature. Conversely, while the E298 Glass laminates exhibit a reduction in $\sim 1 \mathrm{GPa}$ from the dry to saturated laminates, the overall 299 reduction is consistent across the temperature range as evidenced by the parallel lines in the E300 Glass Young's modulus plot. The E-Glass strength also exhibits consistent reductions in 301 strength across the temperature range of consideration. However, the overall reduction in tensile 302 strength for the E-Glass going from a dry to saturated state is significant, nearly $100 \mathrm{MPa}$ in 303 strength corresponding to $30-35 \%$ reductions. 

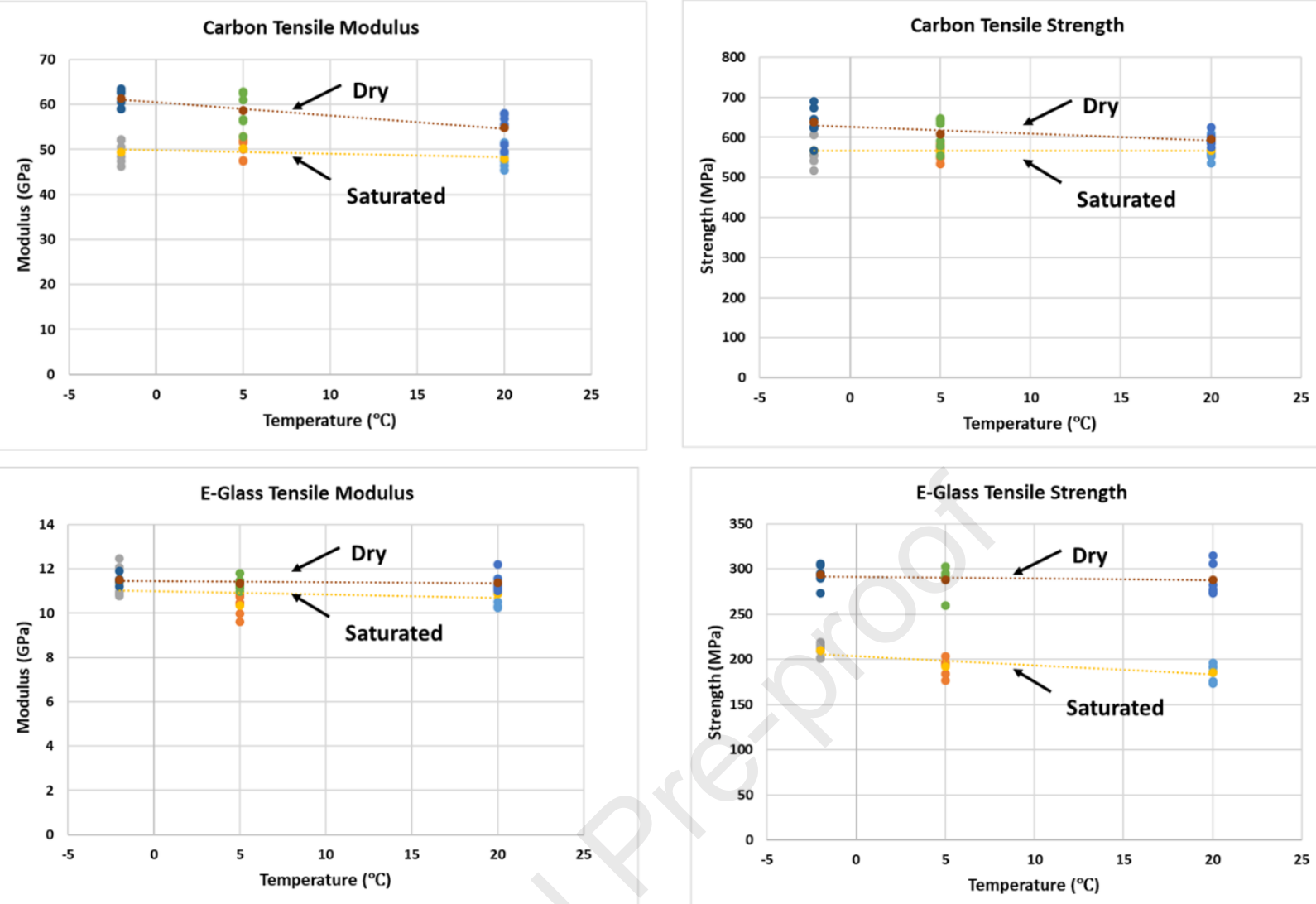

Figure 9 - Laminate Tensile Properties

306

307

Table 1 - Tensile Property Summary

\begin{tabular}{|l|c|c|c|c|c|c|}
\hline \multicolumn{7}{|c|}{ Tensile Summary } \\
\hline
\end{tabular}


310 The specimens after tensile testing are shown in Figure 10 for the dry and saturated samples of

311 the E-glass/Epoxy and Carbon/Epoxy composite laminates. For the E-Glass laminates it is seen

312 that the failure mode in the dry samples was dominated by fiber kinking as evidenced by the slip

313 in the samples after failure, and the large damage area. Very little fiber breakage was observed in

314 this case. Conversely, fiber breakage was the dominant failure mode in the saturated samples

315 with failure mostly happening perpendicularly to the loading direction, leading to very small

316 damage zones. Negligible fiber kinking was observed in the saturated samples. Finally, the

317 effects of temperature could not be seen in the images and the failure modes for all three

318 temperatures were very similar. For the Carbon/Epoxy composites, the postmortem images of

319 the tensile samples can be seen in the lower images of Figure 10. Unlike in the case of the E-

320 glass composites, there was no visible fiber kinking in both the dry and saturated samples.

321 Nevertheless, the saturated samples showed damage on the other end of the sample where the

322 breakage did not occur. This is an indication that there is material degradation caused by water

323 saturation. Lastly, there was no visible variation between samples tested at different temperatures

324 for both the dry and saturated samples. 
Dry
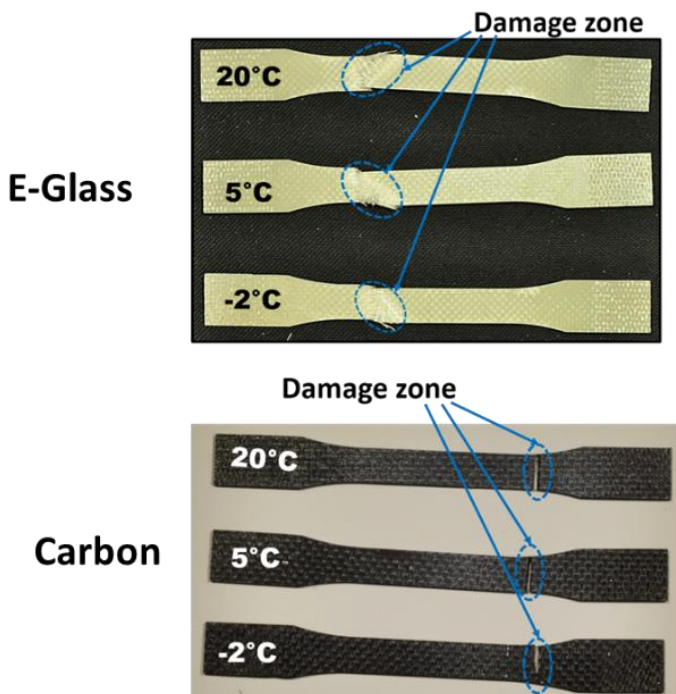

Saturated
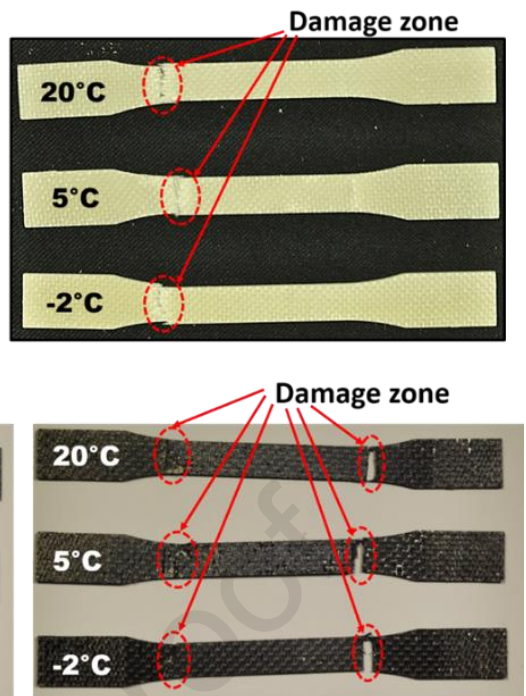

Figure 10 - Tensile Failure Modes and Damage Characteristics

328 The compressive behavior of the Carbon and E-Glass laminates in terms of stiffness and strength

329 as a function of both water saturation and temperature are presented graphically in Figure 11 and

330 summarized in Table 2. Consistent with the tensile tests, all compression experiments were

331 performed at $20^{\circ} \mathrm{C}, 5^{\circ} \mathrm{C}$, and $-2^{\circ} \mathrm{C}$. The effects of both water saturation and temperature on the

332 compressive performance of the materials are clearly seen in each of the respective plots in

333 Figure 11. In terms of stiffness in compression, Carbon exhibits a stiffness of nearly double that

334 of the E-Glass and strengths of 3-4 times larger. This is consistent for both the dry and saturated

335 laminate.

336 The effects of water saturation on the compressive behavior of the respective materials are highly

337 evident in comparing the trend lines in Figure 11 for both Young's modulus and strength. In all

338 cases, at any given temperature there is an overall reduction in properties when the laminates

339 become saturated with water. Observing the magnitudes of the baseline Young's modulus of the

340 respective materials, the compressive Young's modulus exhibits a $40-50 \%$ reduction at $20^{\circ} \mathrm{C}$ due 
341 solely to the presence of the entrained water. At $-2^{\circ} \mathrm{C}$ the overall percentage in magnitude

342 reduction is smaller but still evident, with the reduction in magnitude percentage being

343 attributable to the Young's moduli reduction in the dry laminates. This highlights the

344 observation that the Young's modulus of the saturated panels is constant across all temperatures

345 tested, $3 \mathrm{GPa}$ and 1.5 GPA for the Carbon and E-Glass, respectively. The constant compressive

346 Young's moduli for the saturated panels indicate that the reduction in compressive Young's

347 modulus occurs in the room temperature condition and is significant enough that no further

348 reductions occurs with decreasing temperatures. The compressive strength of the Carbon

349 laminate displays a $30 \%$ reduction at room temperature and a corresponding $10 \%$ reduction at -

$3502{ }^{\circ} \mathrm{C}$. The difference in percent reduction of the strength is the result of differing trends in the dry

351 and saturated laminates as a function of temperature. The dry carbon laminate displays a

352 reduction in strength with decreasing temperature whereas the saturated laminate exhibits an

353 increase in compressive strength with decreasing temperature. The E-Glass compressive

354 strength is reduced $30-40 \%$ overall across the temperature range, with the reduction being

355 slightly higher at the $-2^{\circ} \mathrm{C}$ temperature. This is attributable to the dry laminates showing an

356 increase in strength with decreasing temperatures, whereas the saturated laminates compressive

357 strength is constant across the temperature range of consideration. 

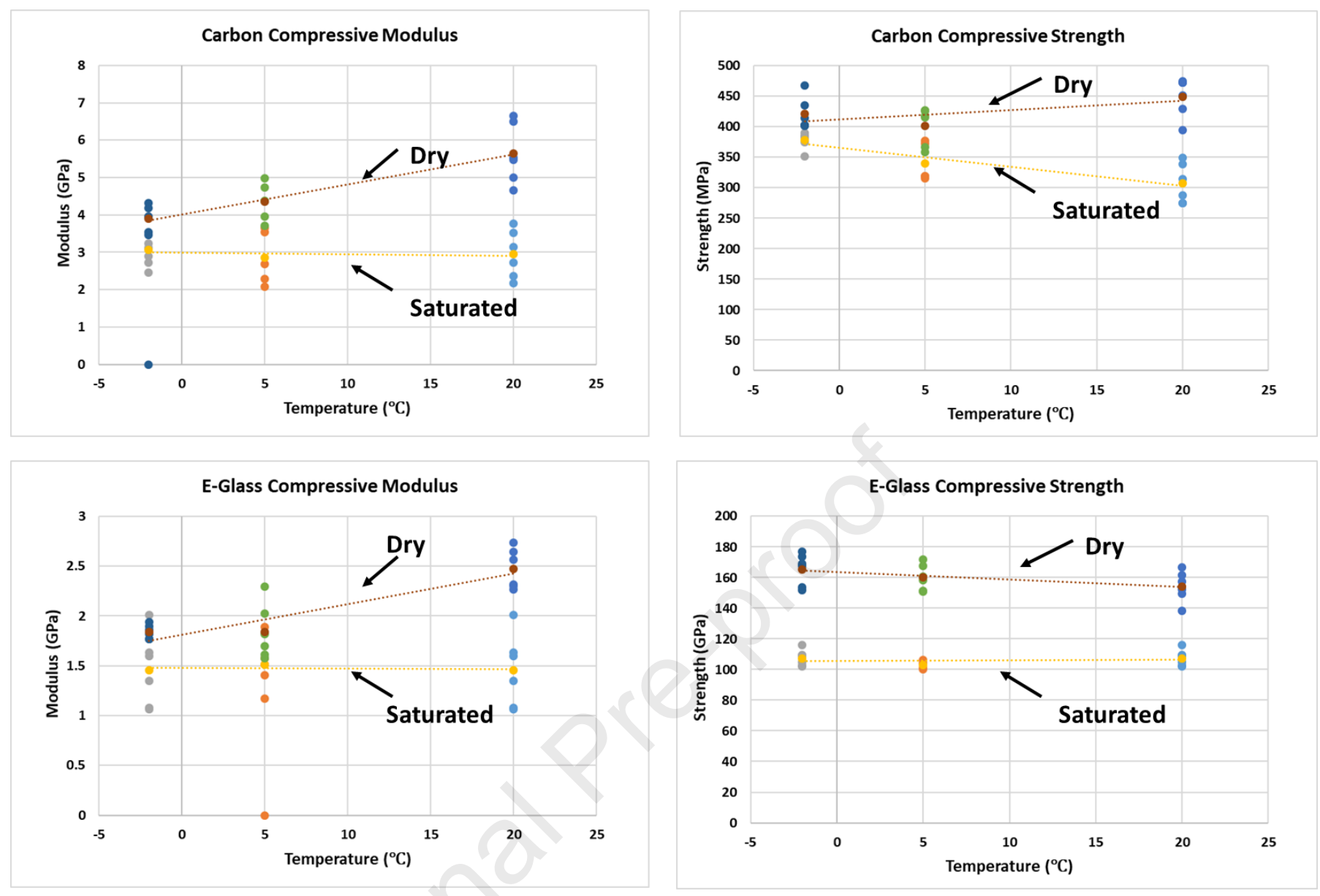
Table 2 - Compressive Property Summary

\begin{tabular}{|c|c|c|c|c|c|c|}
\hline \multicolumn{7}{|c|}{ Compression Summary } \\
\hline & \multicolumn{2}{|c|}{$20^{\circ} \mathrm{C}$} & \multicolumn{2}{|c|}{$5^{\circ} \mathrm{C}$} & \multicolumn{2}{|c|}{$-2^{\circ} \mathrm{C}$} \\
\hline & Dry & Wet & Dry & Wet & Dry & Wet \\
\hline \multicolumn{7}{|c|}{ Carbon } \\
\hline Modulus (GPa) & $5.6+/-0.7$ & $2.94+/-0.5$ & $4.3+/-0.4$ & $2.8+/-0.6$ & $3.8+/-0.3$ & $3.0+/-0.4$ \\
\hline Strength (MPa) & $448+/-29.0$ & $306+/-29.7$ & $401+/-28.0$ & $340+/-28.1$ & $420+/-23.9$ & $378+/-12.6$ \\
\hline \multicolumn{7}{|c|}{ E-Glass } \\
\hline Modulus (GPa) & $2.4+/-0.1$ & $1.45+/-0.3$ & $1.8+/-0.2$ & $1.5+/-0.2$ & $1.8+/-0.06$ & $1.4+/-0.3$ \\
\hline Strength (MPa) & $154+/-9.0$ & $107+/-4.7$ & $160+/-7.7$ & $103+/-2.2$ & $165+/-9.3$ & $107+/-4.7$ \\
\hline
\end{tabular}

367 The characterization of the short beam shear strength trends for the dry and saturated Carbon and

368 E-Glass laminates are graphically highlighted in Figure 12 and summarized in Table 3.

369 Observation of these results show two unique trends in the data. The first is that when the panels

370 are in a fully saturated state there is a net reduction in short beam shear strength across all

371 temperatures, and it is a near uniform reduction of approximately 14 and $6 \mathrm{MPa}$ for the Carbon

372 and E-Glass laminates, respectively. This is apparent by the parallel trend lines in each plot

373 differentiating the saturated and dry laminate short beam shear strengths. The second trend is

374 that for both the dry and saturated laminates, the short beam shear strength increases with

375 decreasing temperature. This increase in strength from $20^{\circ} \mathrm{C}$ to $-2^{\circ} \mathrm{C}$ is on the order of $20 \%$ for 376 each material. 

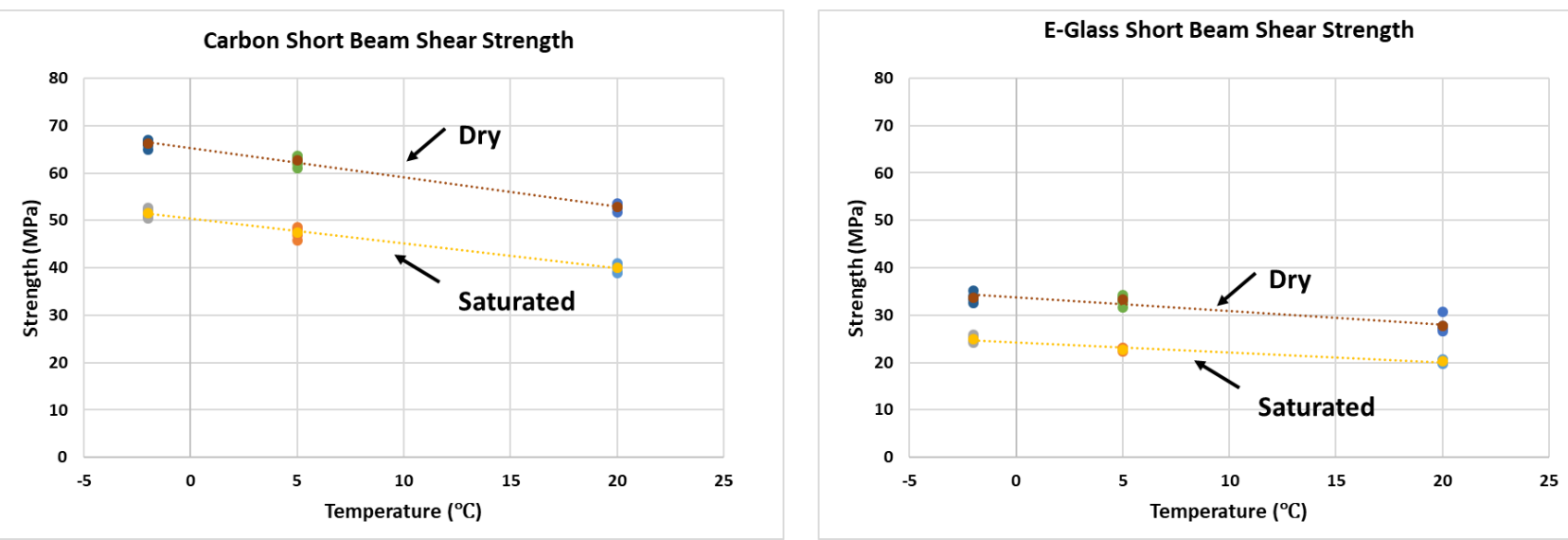

Figure 12 - Short Beam Shear Mechanical Characterization

Table 3 - Short Beam Shear Strength Summary

\begin{tabular}{|l|c|c|c|c|c|c|}
\hline \multicolumn{7}{|c|}{ Short Beam Shear Strength } \\
\hline & \multicolumn{2}{|c|}{$20^{\circ} \mathrm{C}$} & \multicolumn{2}{c|}{$5{ }^{\circ} \mathrm{C}$} & \multicolumn{2}{c|}{$-2^{\circ} \mathrm{C}$} \\
\hline & Dry & Wet & Dry & Wet & Dry & Wet \\
\hline Carbon (MPa) & $52.8+/-0.6$ & $39.9+/-0.7$ & $62.6+/-0.9$ & $47.5+/-0.9$ & $66.1+/-0.6$ & $51.5+/-0.8$ \\
& & & & & & \\
\hline E-Glass (MPa) & $27.7+/-1.3$ & $20.2+/-0.3$ & $32.6+/-0.8$ & $22.8+/-0.2$ & $33.7+/-0.7$ & $25.0+/-0.5$ \\
& & & & & & \\
\hline
\end{tabular}
$\left(G_{\mathrm{IC}}\right)$ of the Carbon and E-Glass laminates are highlighted in Figure 13. From the respective

387 laminate plots, it is observed there is a quantifiable influence of both water absorption and 388 temperature on the dependence of $G_{I C}$, although quite different in nature between the materials. 389 Comparison of the relative dry and saturated $G_{I C}$ trends for the Carbon laminate shows a clear 390 overall reduction in $G_{I C}$ when the laminates become saturated. The reduction is quantified to be 391 on the order of $30-40 \%$ for the respective temperatures. Considering both the saturated and dry 392 conditions for the Carbon laminates, there is less dependence on temperature than the E-Glass 393 laminates where there is a very small decrease in $G_{\mathrm{IC}}$ from $20^{\circ} \mathrm{C}$ to $5^{\circ} \mathrm{C}$, and a statistically 
394 constant value from $5^{\circ} \mathrm{C}$ to $-2^{\circ} \mathrm{C}$ as indicated by the overlapping groupings of the individual 395 samples at these temperatures. The $G_{I C}$ results for the E-Glass laminates exhibit quite the 396 opposite trends as observed in the Carbon laminates in two unique aspects. The first quantifiable 397 trend is observed in the comparison of the saturated and dry laminates in that the $G_{I C}$ increases 398 with the presence of entrapped water. At a temperature of $-2^{\circ} \mathrm{C}$ the increase going from a dry 399 condition to a saturated one is on the order of $100 \%$. Further observation of the E-Glass trends 400 shows that in the dry condition there is a very clear reduction in $G_{I C}$ with decreasing temperature.

401 However, in examining the saturated results, this trend is reversed in that the $G_{I C}$ values exhibit 402 an equally clear increasing $G_{I C}$ with decreasing temperature. The $20^{\circ} \mathrm{C}$ values for both the 403 saturated, and the dry E-Glass laminates are nearly the same and as the temperature is decreased, 404 the $G_{I C}$ values diverge for the saturated, and dry laminates. It is noted that when making these 405 observations, the failure of the carbon laminates is much more interfacial between the plies and 406 dominated by the resin, whereas the E-Glass laminates exhibit much more contribution from the 407 fibers themselves in the form of fiber bridging across the crack front. This indicates that the 408 presence of water saturation influences $G_{I C}$ differently based upon the specific fracture surfaces 409 and mechanics, namely resin vs fiber dominated. 

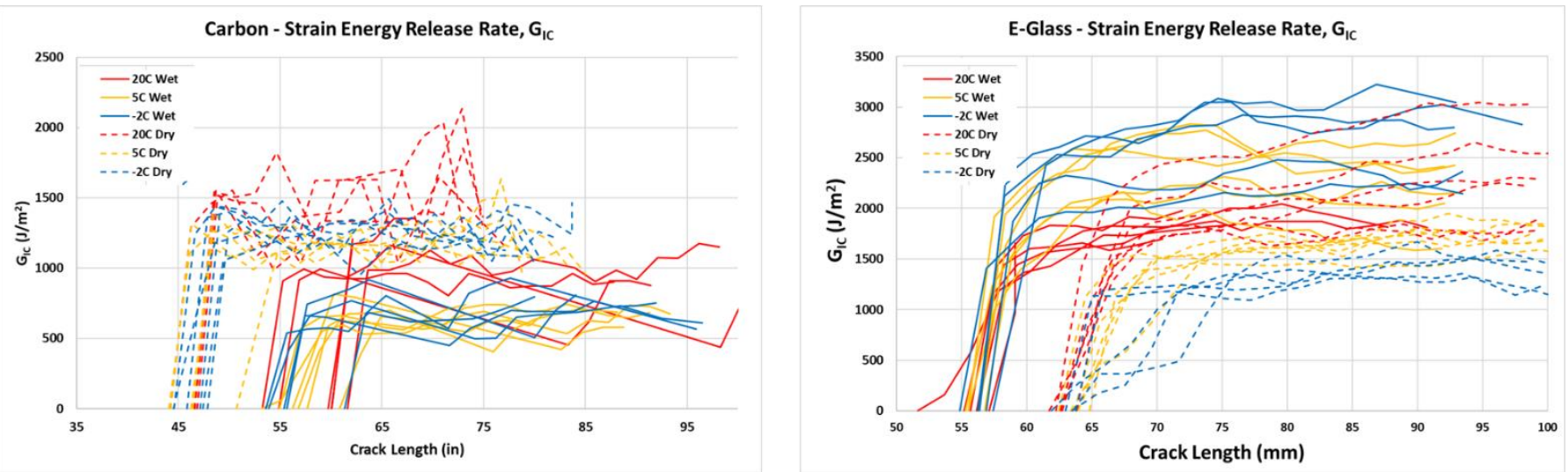

Figure 13 - Static Strain Energy Release Rate $G_{I C}$ vs. Crack Length

Table 4 - Static Mode-I Strain Energy Release Rate Summary

\begin{tabular}{|l|c|c|c|c|c|c|}
\hline \multicolumn{7}{|c|}{ Static Mode-I Strain Energy Release Rate $\left(\mathrm{J} / \mathrm{m}^{2}\right)$} \\
\hline & \multicolumn{2}{|c|}{$20^{\circ} \mathrm{C}$} & \multicolumn{2}{c|}{$5^{\circ} \mathrm{C}$} & \multicolumn{2}{c|}{$-2^{\circ} \mathrm{C}$} \\
\hline & Dry & Wet & Dry & Wet & Dry & Wet \\
\hline Carbon $\left(\mathrm{J} / \mathrm{m}^{2}\right)$ & $1492+/-106$ & $894+/-140$ & $1182+/-54$ & $619+/-50$ & $1239+/-67$ & $808+/-311$ \\
& & & & & & $1366+/-$ \\
E-Glass $\left(\mathrm{J} / \mathrm{m}^{2}\right)$ & $2175+/-418$ & $1777+/-101$ & $1666+/-104$ & $2274+/-310$ & $\begin{array}{c}2724+/- \\
451\end{array}$ \\
\hline
\end{tabular}

419 The dynamic Mode-I critical strain energy release rate, $G_{I C d}$ for the Carbon and E-Glass

420 laminates at each of the temperatures considered and including the effects of water saturation are

421 shown in Figure 14. The loading rate for the E-Glass laminates, taken to be the rate of change of

422 the strain energy release rate with time, was calculated for the dry and saturated E-Glass to be

$423174.8 \mathrm{~kJ} / \mathrm{m}^{2}-\mathrm{s}$ and $148.6 \mathrm{~kJ} / \mathrm{m}^{2}-\mathrm{s}\left(1000 \mathrm{in}-\mathrm{lb} / \mathrm{in}^{2}-\mathrm{s}\right.$ and $\left.850 \mathrm{in}-\mathrm{lb}_{\mathrm{in}}{ }^{2}-\mathrm{s}\right)$ respectively. The Carbon

424 laminate loading rates were $113.6 \mathrm{~kJ} / \mathrm{m}^{2}$-s and $78.6 \mathrm{~kJ} / \mathrm{m}^{2}-\mathrm{s}\left(650 \mathrm{in}-\mathrm{lb} / \mathrm{in}^{2}-\mathrm{s}\right.$ and $\left.450 \mathrm{in}-\mathrm{lb} / \mathrm{in}^{2}-\mathrm{s}\right)$

425 respectively for the dry and saturated states. 
426 The trends in the dynamic fracture results are consistent with the trends observed in the

427 corresponding static experiments, with the primary difference being the magnitudes of the $\mathrm{G}_{\mathrm{IC}}$

428 values. As seen from the Carbon $G_{I C d}$ results, the influence of entrapped water is negligible

429 across the temperature range considered. The $G_{I C d}$ value at the respective temperatures are

430 consistent within the variability of the data. Both the dry and saturated laminates also exhibit

431 near constant values at $20^{\circ} \mathrm{C}$ and $5^{\circ} \mathrm{C}$ with a drop in $G_{I C d}$ going from $5^{\circ} \mathrm{C}$ to $-2^{\circ} \mathrm{C}$. Conversely,

432 the E-Glass laminates show differences between the dry and saturated states. There is a

433 quantitative increase in $G_{I C d}$ value when the E-Glass laminate becomes saturated with water.

434 The net increase in $G_{I C d}$ differs as a function of temperature, from $19 \%$ at $20^{\circ} \mathrm{C}$ up to $52 \%$ at -

$4352{ }^{\circ} \mathrm{C}$. This change in percent increase is similar to the trend seen in the static values where the

436 dry laminates have a decreasing $G_{I C}$ with decreasing temperature and the saturated laminates

437 show an increase in $G_{I C}$ with decreasing temperature. Of significance is the observation that in

438 comparing the dynamic to static values, the $G_{I C d}$ values are markedly lower than the

439 corresponding $G_{I C}$ values. This can be better understood by looking at the interaction of the

440 plastic zone and the carbon or glass fibers at low and high loading rate. Generally, the plastic

441 zone size is directly proportional to the fracture toughness and inversely proportional to the

442 square of the yield stress of the material [19]. Epoxy being a strain rate dependent material has a

443 higher yield stress at high strain rates, which leads to a drastic drop in the plastic zone size and

444 consequently a decrease in the $G_{I C}$ value. In addition, the fracture surfaces shown in Figure 15

445 show that clean interfacial fracture between the fiber surface and the matrix occurred during

446 dynamic experiments in carbon fiber composites. The glass fiber composites showed a mixed

447 fracture surface with still predominant interfacial separation. This interfacial fracture toughness

448 is much lower than the intrinsic fracture toughness of the matrix material. 

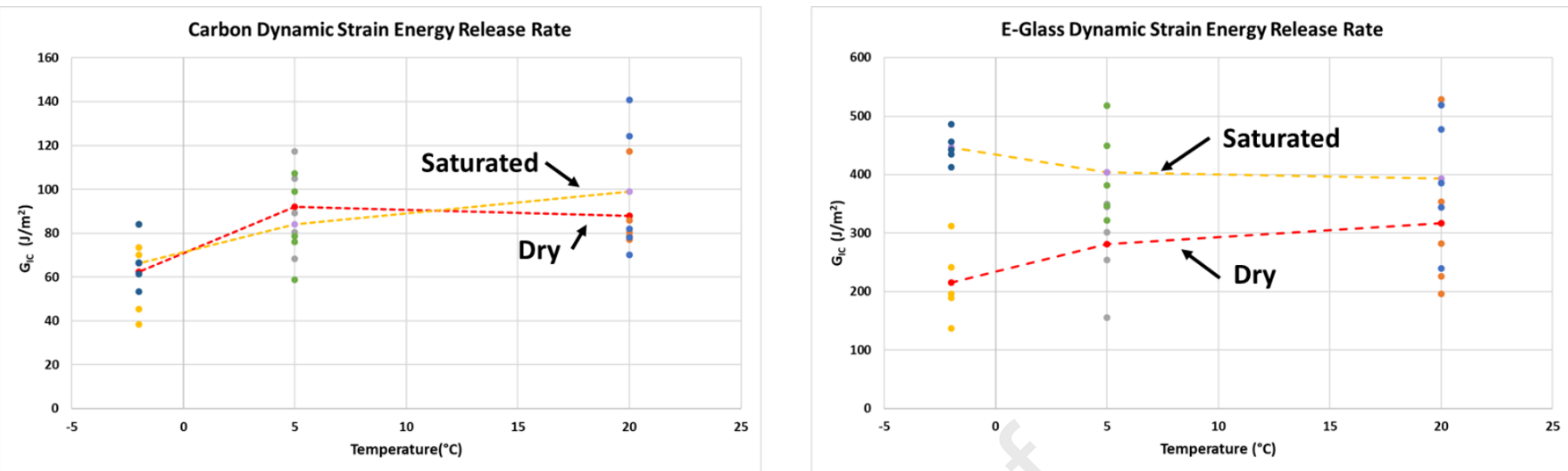

Figure 14 -Dynamic Mode-I Critical Strain Energy Release Rate, $G_{I C d}$

Table 5 - Dynamic Mode-I Strain Energy Release Rate Summary

\begin{tabular}{|l|c|c|c|c|c|c|}
\hline \multicolumn{7}{|c|}{ Dynamic Mode-I Strain Energy Release Rate $\left(\mathrm{J} / \mathrm{m}^{2}\right)$} \\
\hline & \multicolumn{2}{|c|}{$20^{\circ} \mathrm{C}$} & \multicolumn{2}{c|}{$5{ }^{\circ} \mathrm{C}$} & \multicolumn{2}{c|}{$-2^{\circ} \mathrm{C}$} \\
\hline & Dry & Wet & Dry & Wet & Dry & Wet \\
\hline Carbon $\left(\mathrm{J} / \mathrm{m}^{2}\right)$ & $87+/-16$ & $99+/-31$ & $92+/-19$ & $83+/-19$ & $62+/-19$ & $66+/-11$ \\
& & & & & & \\
\hline E-Glass $\left(\mathrm{J} / \mathrm{m}^{2}\right)$ & $317+/-132$ & $393+/-110$ & $281+/-80$ & $403+/-79$ & $214+/-65$ & $446+/-27$ \\
& & & & & & \\
\hline
\end{tabular}
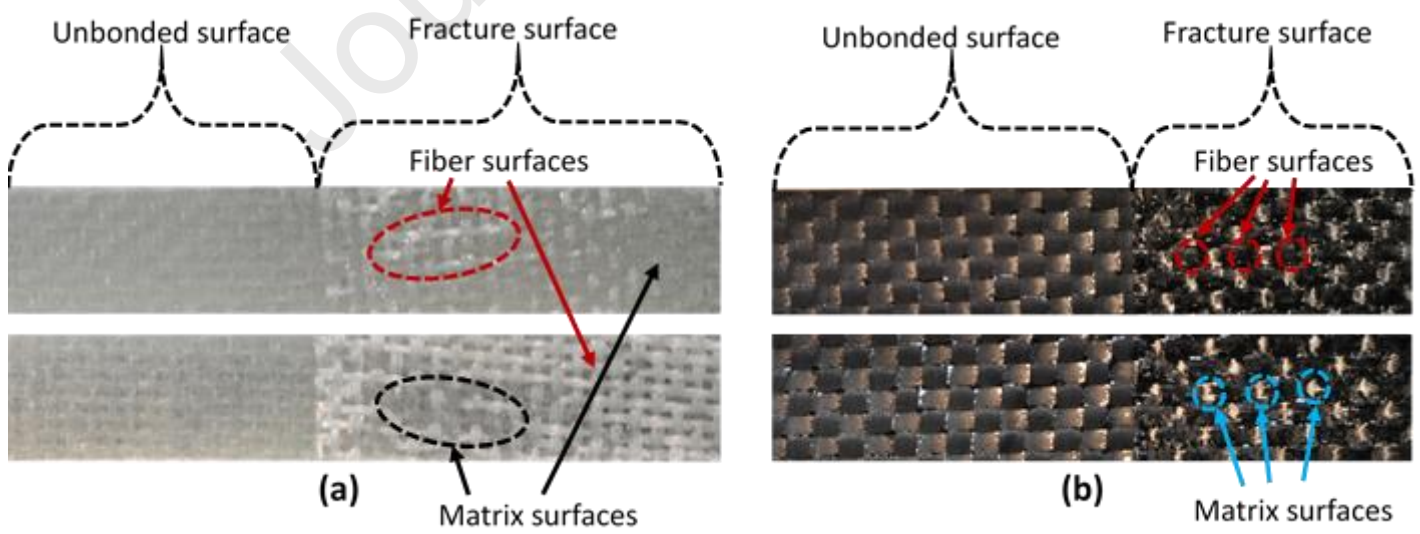
The impact force time histories for the Carbon and E-Glass laminates in the dry and saturated conditions as a function of temperature are provided in the upper plots of Figure 16 as measured by the cross head of the drop tower. While the impact tests were shown to be repeatable from specimen to specimen, only a representative specimen for each temperature is shown for clarity of the time history plot. A summary of the peak impact force is provided in Table 6. In considering these time histories and magnitude comparisons, several key observations can be drawn. The first is that for both the Carbon and E-Glass laminates, the presence of water saturation in the laminates reduces the peak force recorded during the impact event, indicating less stiff laminates under impact loading conditions. The reduction

471 E-Glass laminates similarly show a reduction in peak force during impact, with the 472 magnitude reduction being more significant, $28 \%$ at $20^{\circ} \mathrm{C}$ and $5{ }^{\circ} \mathrm{C}$ and $21 \%-2^{\circ} \mathrm{C}$. For all the 473 laminates peak force increases with decreasing temperature, although the increase is small 474 enough that there is overlap in the data when accounting for the respective data set standard 475 deviations. Furthermore, while the presence of the entrapped water does reduce the overall 476 peak force experienced by the specimens, it does not appear to alter the overall time duration 477 or phasing of the impact event. The peak forces for a given material occur at nearly the same 478 point in time, there is just a reduction in that respective peak force magnitude. Additionally, 479 the damage mechanisms largely remain constant between the dry and saturated laminates for 480 a given material. Primarily, there is brittle type damage for the Carbon laminates after peak 481 impact while there is a controlled ductile like mechanism exhibited by the E-Glass laminates. 482 In the E-Glass materials this is observed as the smoother force-time histories and longer 483 duration of the impactor energy impact event. 
The post-impact four-point flexural behavior of the respective laminates is shown in the lower images of Figure 16 (Note: Due to the large differences in flexural strength the axis limits have not been adjusted for each material). The inherent brittleness of the carbon laminates and their relative thin margin between retaining structural integrity and full failure is highlighted by the amount of scatter in the flexure date for these laminates. Interestingly, the Carbon laminates which have been saturated with water show less variability in the flexure results than the corresponding dry laminates, particularly at the $5^{\circ} \mathrm{C}$ and $-2^{\circ} \mathrm{C}$ temperatures. Furthermore, the saturated Carbon laminates appear to exhibit larger flexure after impact strength than was observed for the dry laminates, between $18 \%$ and $31 \%$ depending on temperature of the testing. This wide range of strength values, even after highly controlled impact experiments, highlights the inherent unknowns and risks when utilizing the Carbon laminates for dynamic / impact loading events. Conversely, the E-Glass exhibits significant reductions in flexure after impact strength when accounting for the presence of water saturation. For the E-Glass laminates tested in flexure after impact at $20^{\circ} \mathrm{C}$ and $5^{\circ} \mathrm{C}$ there is a $44 \%$ decrease in residual flexural strength. Furthermore, the specimens impacted at $-2^{\circ} \mathrm{C}$ sustained complete failure during the impact event (i.e.; zero residual strength). The specimens did remain intact after the impact, but the flexural testing indicated only a minimal resistance to loading and for this reason the $-2^{\circ} \mathrm{C}$ flexural results have not been included in the relevant plot. Overall, for the $20^{\circ} \mathrm{C}$ and $5^{\circ} \mathrm{C}$ results there is a readily observable increase in residual flexural strength with decreasing temperature for the E-Glass laminates. Furthermore, The E-Glass laminates exhibit flexural strain values between 1.25\% and $1.75 \%$ whereas the Carbon laminates have flexural strain values between $0.75 \%$ and $1.1 \%$ 

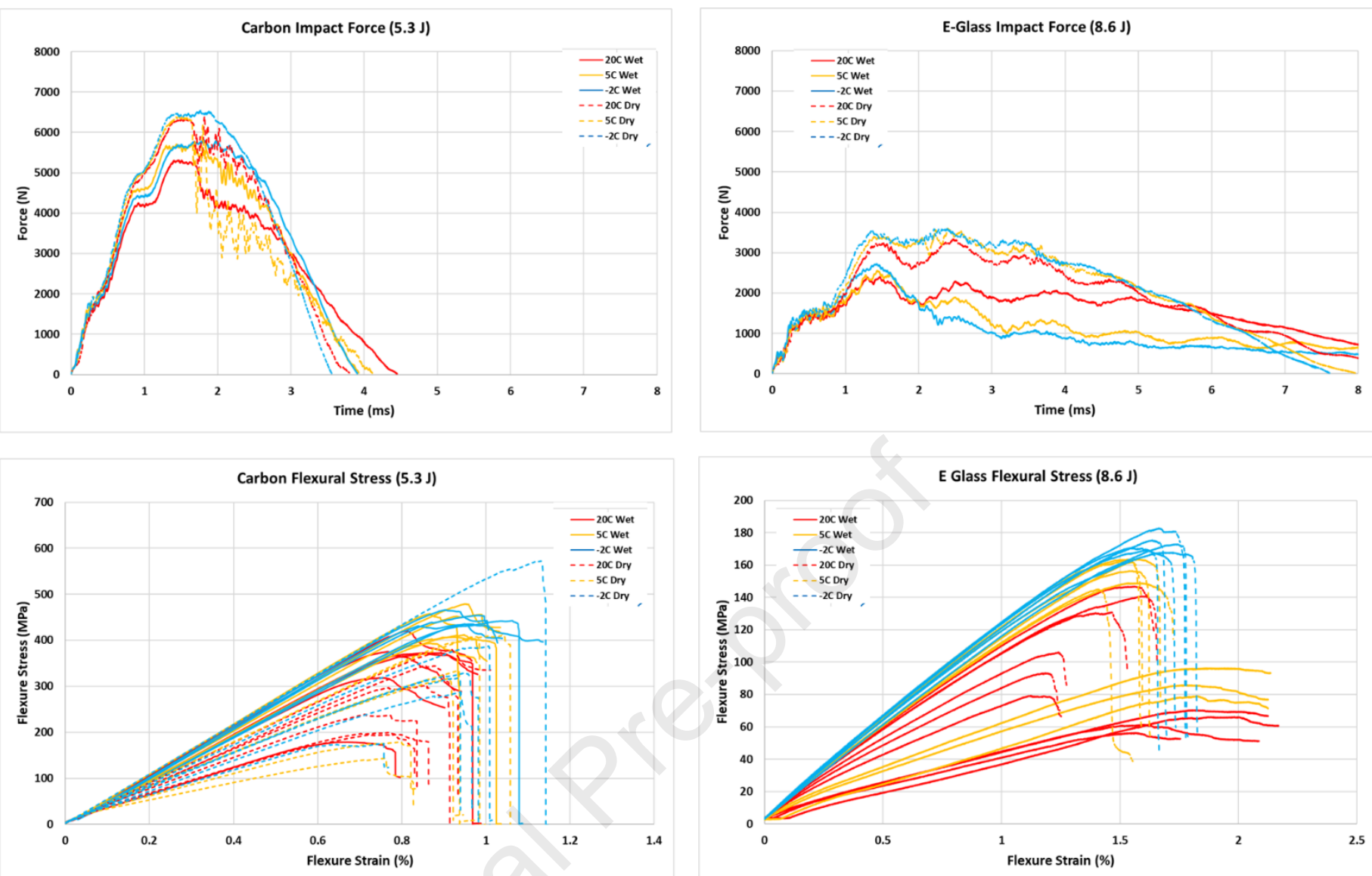

Figure 16 - Impact and Flexure After Impact Performance

510 Table 6 - Peak Impact Force Summary

\begin{tabular}{|l|c|c|c|c|c|c|}
\hline \multicolumn{7}{|c|}{ Peak Impact Force $(\mathrm{N})$} \\
\hline & Dry & Wet & Dry & Wet & Dry & Wet \\
\hline & $6269+/-172$ & $5457+/-281$ & $6358+/-153$ & $5792+/-121$ & $\begin{array}{c}6490+/- \\
160\end{array}$ & $\begin{array}{c}5980+/- \\
176\end{array}$ \\
\hline Carbon $\left(\mathrm{J} / \mathrm{m}^{2}\right)$ & & & & $2507+/-121$ & $\begin{array}{c}3548+/- \\
102\end{array}$ & $2768+/-81$ \\
\hline E-Glass $\left(\mathrm{J} / \mathrm{m}^{2}\right)$ & $3401+/-94$ & $2442+/-96$ & $3608+/-122$ & $2597+{ }^{\circ} \mathrm{C}$ & \\
\end{tabular}


512 Table 7 - Flexural Strength after Impact Summary

\begin{tabular}{|l|c|c|c|c|c|c|}
\hline \multicolumn{7}{|c|}{ Flexural Strength (MPa) } \\
\hline & \multicolumn{2}{|c|}{$20^{\circ} \mathrm{C}$} & \multicolumn{2}{c|}{$5{ }^{\circ} \mathrm{C}$} & \multicolumn{2}{c|}{$-2^{\circ} \mathrm{C}$} \\
\hline & Dry & Wet & Dry & Wet & Dry & Wet \\
\hline Carbon $\left(\mathrm{J} / \mathrm{m}^{2}\right)$ & $277+/-77$ & $339+/-85$ & $298+/-114$ & $433+/-34$ & $345+/-132$ & $446+/-13$ \\
\hline E-Glass $\left(\mathrm{J} / \mathrm{m}^{2}\right)$ & $116+/-27$ & $64+/-6$ & $157+/-8$ & $87+/-9$ & $173+/-6$ & $\begin{array}{c}\text { Failure } \\
\text { Under } \\
\text { Impact }\end{array}$ \\
\hline
\end{tabular}

\section{CONCLUSIONS}

A comprehensive experimental investigation of the effects of water saturation coupled with low temperatures on the mechanical, fracture, and impact dependent material properties of E-Glass/Epoxy and Carbon/Epoxy laminates has been conducted. The primary objective of the study was to quantify the mechanical and damage behavior of these advanced material systems

521 when water saturation is coupled with decreasing temperatures down to the lowest expected

522 water temperatures of the arctic / deep ocean environments. The significant findings of the study

523 highlight that the considerations of the coupled effects of low temperatures and water saturation

524 on composite laminates are critical when designing with these advanced materials. Designing a 525 structure for use in arctic and deep water applications in the absence of detailed material 526 characterization data performed at the expected operating conditions can lead to unexpected and

527 premature failures. It is evident from the investigation that the use of baseline material data

528 taken in controlled laboratory conditions in a dry and room temperature environment are largely

529 insufficient for the design of critical structures to be deployed in low temperature, wetted

530 applications. While not explicitly verified in the current study, it is hypothesized that the 531 presence of full water saturation into the respective laminates results in the presence of 
532 hygrothermal residual stress states which subsequently superimpose on and couple with the

533 mechanical loading during material testing. Furthermore, it is noted that while the current study

534 utilized distilled freshwater in the water ingression aspects of the study, additional work is

535 needed to quantify the effects of salt and/or seawater on the material properties.

536 The key findings of the study were as follows:

\section{- Mechanical Performance}

O Tension: For all temperatures evaluated in the study there are measurable drops in both Young's moduli and tensile strengths with water saturation, although the magnitudes of the drops is dependent upon material property and temperature. For the Carbon laminates, the decrease in Young's modulus and tensile strength is larger at $-2^{\circ} \mathrm{C}$ than at $20^{\circ} \mathrm{C}$. Conversely, the E-Glass material exhibits a near-uniform drop in both moduli and strength in the presence of entrained water over the temperature range. For both the dry and saturated laminates there is an inverse relationship between tensile performance and temperature. exhibit reductions in both compressive Young's modulus and strength when saturated with water as compared to the dry condition. For both laminates evaluated in the study, the water-saturated specimens exhibit a constant Young's modulus with decreasing temperature while the dry laminates exhibit decreasing stiffness with decreasing temperature. The compressive strength of the E-Glass laminate is reduced by $30-40 \%$ across the temperature range. 
○ Short Beam Shear: The short beam shear strength characteristics of the E-Glass and

Carbon/Epoxy laminates display common trends with water saturation and decreasing temperature. In a saturated state, there is a near-uniform decrease in short beam shear strength across the $20^{\circ} \mathrm{C}$ to $-2^{\circ} \mathrm{C}$ temperature range. The experimental results also are characterized by a strength increase with decreasing temperature for both dry and saturated laminates.

\section{- $\quad$ Fracture Performance}

$\circ$ Static Mode-I: Both of the E-Glass and Carbon laminates considered exhibit a direct dependence of $\mathrm{G}_{I C}$ on water saturation and temperature, although opposite effects in nature. The Carbon laminate shows a clear overall reduction in $\mathrm{G}_{I C}$ when the laminates become saturated, on the order of $30-40 \%$ depending on specific temperature. Conversely, for the E-Glass laminate comparison of the saturated and dry condition shows that the $G_{I C}$ increases with the presence of entrapped water. These differences in behavior with saturation appear to be due to the differences in observed failure mode with the Carbon being interfacial ply failure and the E-Glass displaying significant fiber damage. $G_{I C d}$ on water saturation condition at a given temperature. The dry and saturated Carbon laminates each experience drops in $G_{\text {Icd }}$ going from $5^{\circ} \mathrm{C}$ to $-2^{\circ} \mathrm{C}$. Similar to the static Mode-I fracture results, the E-Glass laminates exhibited higher $G_{I C d}$ values in the saturated state than the dry state, from $19 \%$ at $20^{\circ} \mathrm{C}$ up to $52 \%$ at $-2^{\circ} \mathrm{C}$. For 
release rates are significantly lower than the static Mode-I critical strain energy release rates.

○ Impact: The E-Glass and Carbon laminates show lower peak impact forces in a saturated state than the corresponding dry state, an indicator of reduced dynamic flexural stiffness. However, the overall timing, duration, and damage characteristic (brittle versus ductile) of the impact event appears unaffected by the presence of the forces are consistent across the temperature range considered in the study. laminates result in a trend by which the saturated material has higher post-impact water in the material. Each laminate (saturated and dry) displays negligible dependence on impact behavior as a function of temperature as the peak impact flexural strength than the dry Carbon laminates, between $18 \%$ and $31 \%$. However, the E-Glass laminate in a saturated state exhibits a significant reduction in flexure after impact strength as compared to the dry laminate, $\sim 44 \%$ at the two higher temperatures of the study. The saturated E-Glass at $-2^{\circ} \mathrm{C}$ had zero residual strength after impact owing to the complete failure during the impact experiments.

603 The research presented in this study has been generously supported through the Internal 604 Investment Program and In-House Laboratory Independent Research (ILIR) programs at the 
Naval Undersea Warfare Center (Division Newport). The help of undergraduate students Ms.

606 Juliana Martinez and Mr. Timothy Pickard in conducting the dynamic fracture experiments is

607 gratefully acknowledged.

608

609

610

611

612

613

614

615

616

617

618

619

620

621

622

623

624

625

626

627

628

629

630

631

632

633

634

635

636

637

638

639

640

641

\section{REFERENCES}

1. Walsh, R.P., McColskey, J.D., Reed, R.P., "Low Temperature Properties of a Unidirectionally Reinforced Epoxy Fibreglass Composite", Cryogenics 35 (1995) 723725

2. Kim, M., Kang, S., Kim, C., Kong, C., “Tensile Response of Graphite/Epoxy Composites at Low Temperatures", Composite Structures 79 (2007) 84-89

3. Sanchez-Saez, S., Barbero, E., Navarro, C., "Analysis of the Dynamic Flexural Behavior of Composite Beams at Low Temperature", Composites Science and Technology 67 (2007) 2616-2632

4. Ricciardi, M.R., Papa, I., Impero, F., Langella, A., Lopresto, V., Antonucci, V., "LowTemperature Effect on the Impact and Flexural Behavior of Basalt Composite Laminates", Composite Structures 249 (2020)

5. Garcia-Gonzalez, D., Rodriguez-Millan, M., Rusinek, A., Arias, A., "Low Temperature Effect on Impact Energy Absorption Capability of PEEK Composites", Composite Structures 134 (2015) 440-449

6. S. Kichhannagari, "Effects of Extreme Low Temperature on Composite Materials," University of New Orleans Theses and Dissertations, Paper 165, 2004.

7. G. Springer, "Environmental Effects on Composite Materials," Technomic Publishing Co, Inc., 1981.

8. R. M. Jones, "Mechanics of Composite Materials," Hemisphere Publishing Corp., 1975.

9. J. C. Halpin, "Primer on Composite Materials: Analysis," Technomic Publishing Co, Inc., 1984. 
10. LeBlanc, J., Cavallaro, P., Torres, J., Ponte, D., Warner, E., Saenger, R., Mforsoh, I., Shukla, A., "Low temperature effects on the mechanical, fracture, and dynamic behavior of carbon and E-glass epoxy laminates", International Journal of Lightweight Materials and Manufacture 3 (2020) 344-356

15. Cavallaro, P. "Effects of Weave Styles and Crimp Gradients in Woven Kevlar/Epoxy Composites", Experimental Mechancs, 2016, 56:617-635

14. ASTM D2344 / D2344M-16, Standard Test Method for Short-Beam Strength of Polymer Matrix Composite Materials and Their Laminates, ASTM International, West Conshohocken, PA, 2016, www.astm.org

13. ASTM D3410 / D3410M-16, Standard Test Method for Compressive Properties of Polymer Matrix Composite Materials with Unsupported Gage Section by Shear Loading, ASTM International, West Conshohocken, PA, 2016, www.astm.org

12. ASTM D638-14, Standard Test Method for Tensile Properties of Plastics, ASTM International, West Conshohocken, PA, 2014, www.astm.org 
Table 1 - Tensile Property Summary

\begin{tabular}{|c|c|c|c|c|c|c|}
\hline \multicolumn{7}{|c|}{ Tensile Summary } \\
\hline & \multicolumn{2}{|c|}{$20^{\circ} \mathrm{C}$} & \multicolumn{2}{|c|}{$5^{\circ} \mathrm{C}$} & \multicolumn{2}{|c|}{$-2^{\circ} \mathrm{C}$} \\
\hline & Dry & Wet & Dry & Wet & Dry & Wet \\
\hline \multicolumn{7}{|c|}{ Carbon } \\
\hline Modulus (GPa) & $54.8+/-3.3$ & $47.9+/-1.9$ & $58.7+/-3.6$ & $50.2+/-2.1$ & $61.2+/-1.8$ & $49.4+/-2.2$ \\
\hline Strength (MPa) & $595+/-16.0$ & $567+/-24.3$ & $607+/-35.1$ & $563+/-17.4$ & $637+/-39.3$ & $567+/-37.2$ \\
\hline \multicolumn{7}{|c|}{ E-Glass } \\
\hline Modulus (GPa) & $11.3+/-0.4$ & $10.8+/-0.5$ & $11.3+/-0.26$ & $10.3+/-0.4$ & $11.5+/-0.2$ & $11.4+/-0.6$ \\
\hline Strength (MPa) & $288+/-16.1$ & $185+/-8.4$ & $288+/-13.3$ & $191+/-8.9$ & $293+/-10.8$ & $209+/-6.4$ \\
\hline
\end{tabular}

Table 2 - Compressive Property Summary

\begin{tabular}{|c|c|c|c|c|c|c|}
\hline \multicolumn{7}{|c|}{ Compression Summary } \\
\hline & \multicolumn{2}{|c|}{$20^{\circ} \mathrm{C}$} & \multicolumn{2}{|c|}{$5^{\circ} \mathrm{C}$} & \multicolumn{2}{|c|}{$-2^{\circ} \mathrm{C}$} \\
\hline & Dry & Wet & Dry & Wet & Dry & Wet \\
\hline \multicolumn{7}{|c|}{ Carbon } \\
\hline Modulus (GPa) & $5.6+/-0.7$ & $2.94+/-0.5$ & $4.3+/-0.4$ & $2.8+/-0.6$ & $3.8+/-0.3$ & $3.0+/-0.4$ \\
\hline Strength (MPa) & $448+/-29.0$ & $306+/-29.7$ & $401+/-28.0$ & $340+/-28.1$ & $420+/-23.9$ & $378+/-12.6$ \\
\hline \multicolumn{7}{|c|}{ E-Glass } \\
\hline Modulus (GPa) & $2.4+/-0.1$ & $1.45+/-0.3$ & $1.8+/-0.2$ & $1.5+/-0.2$ & $1.8+/-0.06$ & $1.4+/-0.3$ \\
\hline Strength (MPa) & $154+/-9.0$ & $107+/-4.7$ & $160+/-7.7$ & $103+/-2.2$ & $165+/-9.3$ & $107+/-4.7$ \\
\hline
\end{tabular}


Table 3 - Short Beam Shear Strength Summary

\begin{tabular}{|c|c|c|c|c|c|c|}
\hline \multicolumn{7}{|c|}{ Short Beam Shear Strength } \\
\hline & \multicolumn{2}{|c|}{$20^{\circ} \mathrm{C}$} & \multicolumn{2}{c|}{$5{ }^{\circ} \mathrm{C}$} & \multicolumn{2}{c|}{$-2^{\circ} \mathrm{C}$} \\
\hline & Dry & Wet & Dry & Wet & Dry & Wet \\
\hline Carbon (MPa) & $52.8+/-0.6$ & $39.9+/-0.7$ & $62.6+/-0.9$ & $47.5+/-0.9$ & $66.1+/-0.6$ & $51.5+/-0.8$ \\
\hline E-Glass (MPa) & $27.7+/-1.3$ & $20.2+/-0.3$ & $32.6+/-0.8$ & $22.8+/-0.2$ & $33.7+/-0.7$ & $25.0+/-0.5$ \\
\hline
\end{tabular}

Table 4 - Static Mode-I Strain Energy Release Rate Summary

\begin{tabular}{|c|c|c|c|c|c|c|}
\hline \multicolumn{7}{|c|}{ Static Mode-I Strain Energy Release Rate (J/m ) } \\
\hline & \multicolumn{2}{|c|}{$20^{\circ} \mathrm{C}$} & \multicolumn{2}{c|}{$5{ }^{\circ} \mathrm{C}$} & \multicolumn{2}{c|}{$-2^{\circ} \mathrm{C}$} \\
\hline & Dry & Wet & Dry & Wet & Dry & Wet \\
\hline Carbon $\left(\mathrm{J} / \mathrm{m}^{2}\right)$ & $1492+/-106$ & $894+/-140$ & $1182+/-54$ & $619+/-50$ & $1239+/-67$ & $808+/-311$ \\
\hline E-Glass $\left(\mathrm{J} / \mathrm{m}^{2}\right)$ & $2175+/-418$ & $1777+/-101$ & $1666+/-104$ & $2274+/-310$ & $1366+/-113$ & $2724+/-451$ \\
\hline
\end{tabular}

Table 5 - Dynamic Mode-I Strain Energy Release Rate Summary

\begin{tabular}{|c|c|c|c|c|c|c|}
\hline \multicolumn{7}{|c|}{ Dynamic Mode-I Strain Energy Release Rate (J/m ) } \\
\hline & \multicolumn{2}{|c|}{$20^{\circ} \mathrm{C}$} & \multicolumn{2}{c|}{$5{ }^{\circ} \mathrm{C}$} & \multicolumn{2}{c|}{$-2^{\circ} \mathrm{C}$} \\
\hline & Dry & Wet & Dry & Wet & Dry & Wet \\
\hline Carbon $\left(\mathrm{J} / \mathrm{m}^{2}\right)$ & $87+/-16$ & $99+/-31$ & $92+/-19$ & $83+/-19$ & $62+/-19$ & $66+/-11$ \\
\hline${ }^{2}$ E-Glass $\left(\mathrm{J} / \mathrm{m}^{2}\right)$ & $317+/-132$ & $393+/-110$ & $281+/-80$ & $403+/-79$ & $214+/-65$ & $446+/-27$ \\
\hline
\end{tabular}


Table 6 - Peak Impact Force Summary

\begin{tabular}{|c|c|c|c|c|c|c|}
\hline \multicolumn{7}{|c|}{ Peak Impact Force (N) } \\
\hline & \multicolumn{2}{|c|}{$20^{\circ} \mathrm{C}$} & \multicolumn{2}{c|}{$5^{\circ} \mathrm{C}$} & \multicolumn{2}{c|}{$-2^{\circ} \mathrm{C}$} \\
\hline & Dry & Wet & Dry & Wet & Dry & Wet \\
\hline Carbon $\left(\mathrm{J} / \mathrm{m}^{2}\right)$ & $6269+/-172$ & $5457+/-281$ & $6358+/-153$ & $5792+/-121$ & $6490+/-160$ & $5980+/-176$ \\
\hline E-Glass $\left(\mathrm{J} / \mathrm{m}^{2}\right)$ & $3401+/-94$ & $2442+/-96$ & $3608+/-122$ & $2597+/-121$ & $3548+/-102$ & $2768+/-81$ \\
\hline
\end{tabular}

Table 7 - Flexural Strength after Impact Summary

\begin{tabular}{|c|c|c|c|c|c|c|}
\hline \multicolumn{7}{|c|}{ Flexural Strength (MPa) } \\
\hline & \multicolumn{2}{|c|}{$20^{\circ} \mathrm{C}$} & \multicolumn{2}{c|}{$5{ }^{\circ} \mathrm{C}$} & \multicolumn{2}{c|}{$-2^{\circ} \mathrm{C}$} \\
\hline & Dry & Wet & Dry & Wet & Dry & Wet \\
\hline Carbon (J/m ${ }^{2}$ & $277+/-77$ & $339+/-85$ & $298+/-114$ & $433+/-34$ & $345+/-132$ & $446+/-13$ \\
\hline E-Glass $\left(\mathrm{J} / \mathrm{m}^{2}\right)$ & $116+/-27$ & $64+/-6$ & $157+/-8$ & $87+/-9$ & $173+/-6$ & Failure Under Impact \\
\hline
\end{tabular}


Dr. James LeBlanc

26 April 2021

Dear Editor,

The authors have no financial or other conflicts of interest associated with the manuscript for submission.

Thank You, James LeBlanc 